\title{
El influjo del Derecho Indiano en la legislación sobre ejidos de la Provincia de Buenos Aires, 1782-1870
}

\author{
por \\ María Fernanda Barcos \\ CONICET/CEHR-IdIHCS (Universidad Nacional de La Plata)
}

\begin{abstract}
Los pueblos de la actual provincia de Buenos Aires se fueron conformando mayormente de manera espontánea, a medida que se asentaba la población y se avanzaba sobre el espacio apropiado a los indígenas; en la mayoría de los casos al amparo de los fuertes o las capillas. Los ejidos de esos pueblos existian de hecho como tierras de pan llevar pero se trazaron formalmente recién durante el siglo XIX. A lo largo de este trabajo se analizará el modo en que se operó la construcción de un cuerpo jurídico para los ejidos bonaerenses poniendo especial interés en la influencia del derecho indiano.
\end{abstract}

Palabras Clave: ejidos; pueblos; Buenos Aires; Derecho Indiano; donaciones; propiedad; labradores.

[...] guiémonos entonces por las leyes de España y hagamos lo que mandó Carlos V cuando dispuso que las estancias no se poblaran sino en lugares yermos; que toda vez que hubiera poblados y quintas se mandaran retirar las estancias ${ }^{1}$.

Diputado Miguel Navarro Viola, 12 de septiembre de 1856.

\section{INTRODUCCIÓN}

La problemática ejidal es uno de los aspectos menos conocidos de la historia rural de Buenos Aires a pesar de ser un tópico recurrente de la historiogra-

1 Diario de Sesiones de la Cámara de Diputados de la Provincia de Buenos Aires. Sesión del 12 de septiembre de 1956: 391. 
fía agraria latinoamericana y española. Dicho vacío de información se relaciona con las posturas dominantes que circularon durante años dentro de la disciplina y que diferenciaban tajantemente la primera parte del siglo, definiéndola por el predominio de la gran propiedad, la extrema escasez de población y la omnipresencia de la producción ganadera; con la expansión posterior a 1860. Dentro de esta lógica, los pueblos rurales eran descritos como espacios rudimentarios y sus habitantes desapercibidos puesto que la mirada centrada en «la estancia» opacaba cualquier interés sobre los labradores y pastores que habitaban allí. En contrapartida, el periodo posterior, caracterizado por la economía exportadora, emergía naturalmente y basaba su dinamismo en factores fundamentalmente externos (capital y mano de obra). A partir de ese momento, los poblados cobraban interés historiográfico puesto que se convertían en importantes núcleos de población debido a la llegada de la inmigración europea ${ }^{2}$.

Desde hace más de dos lustros, la historiografía argentina ha erosionado gran parte de los postulados que sostenían la imagen dicotómica entre periodos y ha profundizado el análisis de varios aspectos de la economía, la sociedad y la política bonarense del XIX. Esta renovación permitió descubrir muchas continuidades y no tantas rupturas, pero sobre todo evidenció dos aspectos estructuralmente fundamentales: la diversidad de situaciones que existieron en torno a la ocupación de la tierra y la existencia de una intrincada red social que se fue desarrollando desde fines del siglo XVIII incentivada por el constante ingreso de migrantes del interior del país. Estos pobladores, atraídos por la frontera porteña que se expandía (ver mapa), ocuparon nuevas tierras y pueblos aumentando tempranamente la capacidad productiva de la provincia. Hoy sabemos que si bien la actividad agrícola no fue preponderante hasta fines del siglo XIX no por ello dejó de practicarse desde tiempos coloniales en tierras cercanas a la ciudad, en los ejidos, en los espacios que las deficientes mediciones de la época dejaban entre estas grandes unidades e incluso en las estancias ${ }^{3}$.

Los aportes señalados renovaron el estado del conocimiento brindando una plataforma de conocimientos nuevos que permiten hoy replantear el tema de los pueblos y específicamente de los ejidos desde diferentes ópticas. En el siguiente trabajo nos proponemos tomar solo uno de estos aspectos y analizarlo en profundidad: la construcción histórica de un cuerpo jurídico para regular el uso, función y otorgamiento de tierras en los ejidos de los pueblos

\footnotetext{
2 Cárcano, 1972 [1917]. Bejarano, 1969: 75-149.

3 Existen trabajos que han sintetizado gran parte de la labor historiográfica de los últimos veinte años. Gelman y Barsky, 2001. Fradkin y Gelman, 2004: 31-54. Fradkin, 2006: 189200.
} 
Mapa: Avances de la frontera en Buenos Aires, siglo XVIII y XIX*

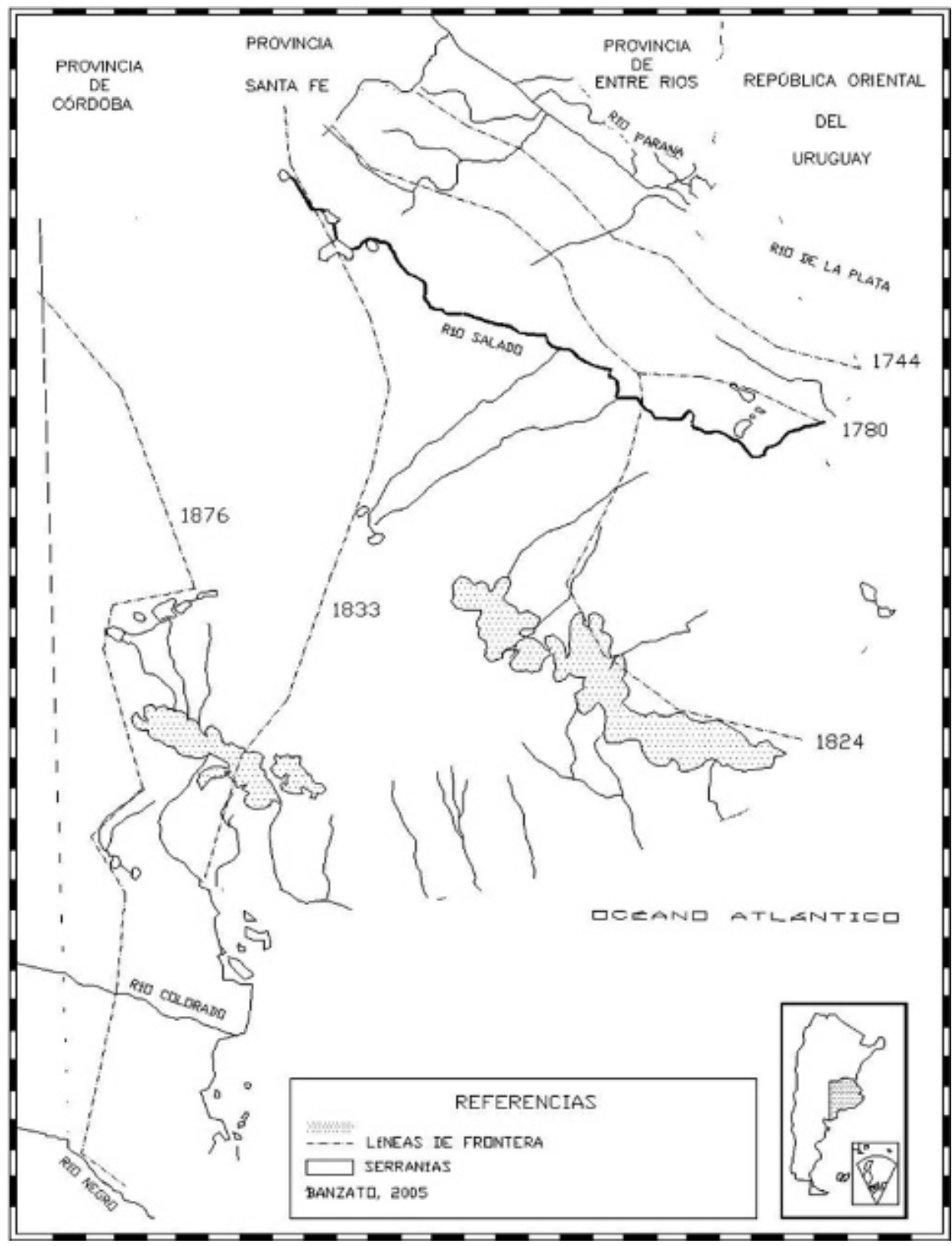

* Agradezco a Guillermo Banzato por facilitarme el mapa de referencia. 
de la campaña de Buenos Aires. Para ello, creímos relevante prestar especial atención a la influencia del derecho indiano en el cúmulo de proyectos y disposiciones sancionados entre 1810-1870 puesto que es allí y en la aplicación de estas normas - más aún en los intersticios - donde claramente se observan las continuidades y cambios con el periodo colonial como las tensiones que el impulso reformador y modernizador de mediados de siglo generó en el seno la sociedad rural debido a la multiplicidad de formas de concebir los ejidos y la propiedad. Se estudiarán entonces los antecedentes coloniales en materia de pueblos y poblaciones, los informes de los funcionarios coloniales, las leyes del periodo independiente y los debates suscitados en las cámaras de senadores y diputados de la Provincia de Buenos Aires durante el periodo codificador ${ }^{4}$.

\section{Pueblos, POBLACIONES Y EJIDOS DURANTE LA COLONIA}

En Buenos Aires, como en el resto de América hispánica, las normativas sobre el uso y la función de los ejidos encontraron su fundamento más temprano en el Derecho Indiano. Mucho se ha discutido sobre la definición de este sistema normativo sin lograr un acuerdo general, pero sí un consenso medianamente aceptado 5 . En este sentido, consideramos que el Derecho Indiano es el derecho que «rigió» en las Indias aunque puede diferenciarse un Derecho Indiano General o en sentido amplio (que incluyó el Derecho de Castilla - el Fuero Real y Las Partidas - como así también los usos y costumbres de los indígenas) y un Derecho Indiano en sentido estricto (conjunto de leyes dictadas específicamente para las Indias). Recientemente se ha prestado también atención a la influencia del Derecho Común romano-canónico siendo este Ius Commune del castellano y el castellano Ius Commune del Indiano. Por último, se ha señalado la importancia de prestar atención a los usos y costumbres de los africanos ${ }^{6}$. En este trabajo nos referiremos al Derecho Indiano en sentido amplio, como veremos posteriormente, la problemática ejidal en el Río de la Plata fue analizada por los especialistas en jurisprudencia y percibida por los contemporáneos en este sentido.

${ }^{4}$ Se deja conscientemente de lado las características que adoptaron los ejidos en otras regiones de Argentina por las particularidades de Buenos Aires. Ver por ejemplo: Page, LXIV/232 (Madrid, 2004): 635-650. Tell, 20 (La Plata, 2010): en línea.

5 Zorraquín Becú, 22 (Buenos Aires, 1994): 401-417; 25 (Buenos Aires, 1997): 501-524. Tau Anzoátegui, 21 (Buenos Aires, 1993): 41-51.

6 Martiré, 29 (Buenos Aires, 2001): 333-363. 
Puesto que las disposiciones que integraron lo que se denominó posteriormente «Derecho Indiano» no pretendieron nunca ser completas ni abarcadoras de varias regiones sino, en cambio, resolver situaciones concretas, una de sus características fue su pronunciado «casuismo». A pesar de ello, y por la multiplicidad de normas que se fueron generando a través de los años, se proyectaron varias recopilaciones que pretendieron generar un ordenamiento general a las Indias. El resultado más acabado fue la Recopilación de Leyes de los Reinos de Indias de $1680^{7}$. Junto a esta obra existieron también un conjunto de disposiciones de origen local - Derecho Indiano Local - que regularon varios aspectos de la vida en América y «la costumbre» también se erigió en fuente de derecho ${ }^{8}$. Las disposiciones de la Recopilación se mantuvieron bastante vigentes aún con las modificaciones que se realizaron en el siglo XVIII e incluso se aplicaron en mayor medida durante el reinado de los Borbones, a pesar de que estos últimos se diferenciaron de los Austrias en cuanto a las políticas para el Nuevo Mundo9. Las normas señaladas en el libro IV título VII de la Recopilación establecían la finalidad que tenían los ejidos en los pueblos de españoles. De los terrenos reservados, eran el área destinada al posible aumento de la población:

El termino y territorio, que fe diere á poblador por capitulación, fe reparta en la forma siguiente: saquese primero lo que fuere menester para los folares del Pueblo y exido competente, y deheffa en que pueda paftar abundantemente el ganado, que han de tener los vecinos, y más otro tanto para los propios del lugar: el refto de el territorio y termino fe haga quatro partes: la una de ellas, que efcogiere, fea para el que efta obligado a hacer el Pueblo, y las otras tres fe reparten en fuertes iguales para los pobladores ${ }^{10}$.

En cuanto a los ejidos se estipulaba: «[...] fean en tan competente diftancia, que fi creciere la población, siempre quede baftante efpacio, para que la gente fe pueda recrear, y falir los ganados fin hacer daño» ${ }^{11}$. Una vez adjudicadas las tierras de labor (que no eran las ejidales) se ordenaba comenzar a poblar el área que implicaba: construir sementera, edificar y empalizar. Debido a la dificultad para contener el ganado y los males que este «acarreaba» en las zonas sembradas se ordenaba que:

Luego, y fin dilación, que las tierras de labor fean repartidas, siembren los pobladorestodas las femillas que llevaren, y pudieren haber, de que conviene que vayan

7 Tau Anzoategui, 21 (Buenos Aires, 1993): 41-51.

8 Tau Anzoategui, 1986. Martiré, 29 (Buenos Aires, 2001): 333-363.

9 Tau Anzoategui, 21 (Buenos Aires, 1993): 41-51.

10 Recopilación de leyes de los Reynos de las Indias, 3 Vols., Madrid, 1791, Libro IV, Título VII (En adelante: Recopilación).

11 Ibidem., Libro IV, Título VII, Ley XIII. 
muy proveídos; y para mayor facilidad, el Governador dispone una perfona, que ocupe ensembrar y cultivar la tierra de pan y legumbres, de que luego fe puedan foccorrer: y en la dehesa echen todo el ganado que llevaren, y pudieren juntar, con fus marcas y feñales, para que luego comience á criar y multiplicar, en partes donde este seguro, y no haga daño en las heredades, sementeras, ni otras cofas de los Indios ${ }^{12}$.

Como podemos observar, esta primera definición trasplantada a América consideraba «ejido» a las tierras a la salida de los poblados, del mismo modo que en Castilla. Así, en los pueblos españoles, el ejido estuvo destinado al posible aumento de la población y para conducir el ganado a la dehesa; en cambio, en los pueblos de indios, fue uno de los cuatro tipos de tierra comunal protegida por la Corona: fundo legal, ejidos, propios y tierras de común repartimiento. Claramente debemos tener en cuenta que en varias oportunidades existieron diferencias entre los usos reales sancionados y las prácticas cotidianas de apropiación del espacio tanto por los efectos de la legislación indiana local como por la costumbre. Por otra parte, estas ordenanzas que provenían del derecho castellano fueron incorporadas a la Recopilación de 1680 en un periodo donde ya no estaba tan consensuada la idea del aprovechamiento común de pastos. Posteriormente, esta falta de consenso se transformó en una postura opuesta a los usos comunes en consonancia con las nuevas ideas de corte individualista del siglo XVIII ${ }^{13}$. Además, como el universo jurídico indiano era amplio, se hicieron tanto excepciones como ajustes y adecuaciones a lo que postulaba la Recopilación ${ }^{14}$. Los matices enunciados no invalidan el hecho de que fue esta la principal fuente de derecho durante todo el periodo colonial.

Tanto los «ejidos» como los «propios» eran tierras municipales por lo cual estaban bajo administración de los cabildos o los ayuntamientos. Si bien la diversidad de regiones y casos impide generalizar, lo que está claro es que estos organismos otorgaron de manera diversa los terrenos: los concedieron en arrendamiento e incluso los enajenaron y también existieron casos donde los ayuntamientos defendieron el ejido frente a los particulares o a otros cabildos ${ }^{15}$. Fuera de estas reservas, las mercedes reales fueron la modalidad más frecuente de adjudicación de la tierra. El que no recibía la tierra en merced debía comprarla en pública subasta o en moderada composición. Desde el punto de vista legal, estos repartos debían otorgarse fuera de pueblos y ejidos

\footnotetext{
12 Recopilación, Libro IV, Título VII, Ley XXVI.

13 Mariluz Urquijo, 1978.

14 Tau Anzoategui, 8 (Buenos Aires, 1980): 331-395.

15 Ots Capdequí, 1946: 144.
} 
ya que las leyes indianas protegían los poblados. Se ha demostrado que en zonas centrales, como por ejemplo Nueva España, las normas no siempre fueron respetadas y la usurpación se dio constantemente ${ }^{16}$.

Promediando el siglo XVIII el estado español elaboró La Real Instrucción de 1754. El ordenamiento obedecía a la necesidad de lograr un mayor control fiscal puesto que no se había logrado regularizar la situación de muchos propietarios mediante la Moderada Composición. Este conjunto de leyes instruía a los funcionarios de la Corona que nombraran ministros para ejercer la venta de las tierras y baldíos y establecía normativas sobre las tierras ejidales de los pueblos indígenas:

En lo que se refiere a las de comunidad, y las que les están concedidos a sus pueblos para pastos y ejidos se mantendrá la posesión de ellas y reintegrándolos en las que se les hubiesen usurpado, concediéndoles mayor extensión en ellas, según la exigencia de la población; no usando tampoco de rigor con las que ya poseyeren los Españoles y gente de otras castas $[\ldots]^{17}$.

A pesar de los intentos de reforma, los resultados a largo plazo no fueron los esperados debido a la imposibilidad de la Corona de ejercer un control efectivo que le permitiera hacer cumplir las leyes. Por otra parte, los intereses particulares que se habían creado en América tras siglos de colonización influyeron en las decisiones de los funcionarios. En cuanto a los pueblos españoles y sus ejidos, la política de los Borbones modificó en parte lo estipulado siglos atrás ya que el objetivo del nuevo modelo colonizador consistió en fundar pueblos de labradores que mantuvieran la cuadrícula como elemento sustancial, pero que a su vez definieran una organización de viviendas y la propiedad de un lote de tierra cultivable ${ }^{18}$. Si bien la Corona respetó desde lo legislativo los diferentes tipos de propiedad comunal, la protección comenzó a menguar con estas disposiciones que consideraban positivo la reducción de los comunales a la propiedad individual, sobre todo a partir del reinado de Carlos III; y no solo en América sino también en España ${ }^{19}$.

Mientras se producían las modificaciones señaladas en el apartado anterior, Buenos Aires constituía un área de frontera y por eso la preocupación por la formación de pueblos estuvo desde el inicio ligada sobre todo a las

16 Cárcano, 1972 [1917]: 4-5. Mendieta y Núñez, 1964. Eckstein, 1966. De la Peña, 1980. Bellingeri y Gil Sánchez, 1980: 97-118. Knowlton, XLVIII/1 (México, 1998): 71-96.

17 Real Instrucción del 15 de Octubre de 1754. Transcripta por Orozco, 1895: 270.

18 Aliatta, 1998: 199-248.

19 Menegus y Cerrutti, 2001: 71-90. Peset, 2001: 13-43. Samudio, LXXXIX/353 (2006): 63-98. 
tareas de defensa (ver mapa) ${ }^{20}$. La sucesión alternada de periodos de paz y etapas más conflictivas fue una constante de la dinámica relacional de las comunidades aborígenes y la sociedad hispano-criolla. A mediados de siglo XVIII los conflictos recrudecieron y por eso la Corona se vio obligada a reorganizar su plan defensivo, lo que incluyó asegurar las zonas más peligrosas y formar compañías armadas y fijas en la frontera ${ }^{21}$.

\section{Pedro Andrés García y la cuestión ejidal}

A fines del siglo XVIII circulaban en las esferas intelectuales de Buenos Aires las nuevas doctrinas económicas liberales, pero estas llegaron mediadas por la particular mirada de los ilustrados españoles quienes aún no habían podido desprenderse de los principios mercantilistas y fisiócratas ${ }^{22}$. Bajo estas heterogéneas influencias (por ejemplo, las obras de Jovellanos o Campomanes) la agricultura era considerada por los pensadores de la época (Vieytes y Belgrano, entre otros) la madre de todas las riquezas y para protegerla se consideraba importante sostener, sobre todo, la seguridad de los individuos y el derecho de propiedad ${ }^{23}$. En la misma sintonía ideológica, pero en un periodo en el cual el impulso ganadero era más notable, se expresaron los escritos de Pedro Andrés García ${ }^{24}$. Funcionario de la Corona y posteriormente de los gobiernos revolucionarios, García representó el tránsito de un periodo al otro ya que fue él quien reelaboró el conjunto de normas sobre pueblos y poblaciones presentes en la legislación indiana al contexto pampeano. La preocupación por la frontera, la reunión de la población en torno a pueblos y la conformación de los ejidos fueron parte de sus preocupaciones:

[...] para hacer útil al Estado esta más numerosa porción de habitantes de la campaña, para que ésta progrese y produzca cuanto su ferocidad promete es de absoluta necesidad reducirlos a poblaciones, distribuirles tierras, poner coto y términos en los pastos y aguadas, deslindar las propiedades, y beneficiar los realengos, estableciendo antes los terrenos de pan llevar a diferencia de las estancias, dilatando

$20 \mathrm{Si}$ bien se confeccionaron algunas disposiciones sobre ejidos tempranamente como la Real Cédula del 10 de septiembre de 1546, los actos efectivos fueron mínimos (Storni, 28 (Buenos Aires, 2000): 628.

21 Carbia, 1930. Cabodi, 1952. Marfany, 1961. Barba, 1997. Mandrini, 1997: 23-34. Mayo, 1998. Areces, 1999: 25. Ratto, 2003.

22 Chiaramonte, 1982. Reguera, 2009: 21-34.

23 Reguera, 2009.

24 Gelman, 1997. 
unos y otros, por no ser ya bastantes los detallados en la fundación de la ciudad en razón de su considerable aumento de población ${ }^{25}$.

En los informes de García se observa claramente como aún estaba vigente la idea de otorgar, por lo menos en parte, un carácter común a los ejidos aunque también consideraba necesario ponerles coto, en consonancia con la mirada ilustrada ${ }^{26}$. En el párrafo siguiente notamos el cambio respecto a la función que debían tener los ejidos:

La opresión en que casi hasta nuestros tiempos ha tenido el indio infiel a aquellos pobladores, y sus descendientes pudo haber contribuido a hacer indistintamente uso de los terrenos, abandonado por necesidad el sistema fundador y policía necesaria; siendo muy digno de notar, que un pueblo naciente, destinase 11 leguas para siembras después de dejar a la ciudad 1 de ejido, el competente para huertas, francas las entradas, y libres los pastos y aguadas de las barrancas altas hasta las barranquillas o lengua del agua del Río de La Plata para el uso del vecindario que hoy no tiene, y ha hecho desaparecer la codicia de unos y el abandono de otros en perjuicio de la salud pública y general comodidad ${ }^{27}$.

Las once leguas correspondían a «tierras de pan llevar», es decir, a tierras de labor destinadas para chacras, la legua restante era para el ejido y se la designaba de uso libre (como entrada de la población) para pastos y aguadas. Si bien los historiadores colonialistas coinciden en señalar que las Leyes de Indias no estipularon un límite a la extensión de los ejidos, usualmente se establecía una legua de largo ${ }^{28}$. Además de las tierras inmediatas a la ciudad, García postulaba que las tierras que rodeaban los pueblos también debían ser destinadas a la agricultura de modo exclusivo: «No se permitirá en ellos estancia alguna, ni se criará en ellas más ganado mayor que el que los labradores necesiten para sus trabajos $[\ldots]$... . Por otra parte, era de absoluta necesidad la acción técnica de especialistas para efectuar los planos topográficos, las mensuras de las tierras de la campaña y la zonificación que «[...] designe término a los terrenos de pan llevar, a diferencia de los de ganados $[. .].\rangle^{29}$. Proponía también tres formas en las que el productor directo debía vincularse con la tierra y que tenían que privilegiarse: donación, arrendamiento y, si fuera posible, venta.

En cuando a la influencia del Derecho Indiano, como bien planteó Aliata ${ }^{30}$, a pesar de las «nuevas ideas ilustradas», las características de las trazas de los

25 «Antología de Pedro A. García, 6 de septiembre de 1810», Gelman, 1997: 57.

26 Ibidem: 64.

27 Idem.

28 Orozco, 1895. Mendieta y Núñez, 1964.

29 Antología de Pedro A. García, 1811. Gelman, 1997: 26.

30 Aliata, (París, 2010): en línea. 
poblados de Buenos Aires obedecieron mucho más al modelo indiano que al de los reformadores borbónicos. Según el autor, el sistema indiano, más allá del uso de la cuadrícula, formuló una zonificación igualmente radiocéntrica, pero con otras connotaciones ${ }^{31}$. En cuanto a los ejidos de esos pueblos, existían de hecho, pero aún no estaban trazados, por eso la noción existía entre los pobladores puesto que se había transmitido a través de la costumbre asociada al concepto de «tierras de pan llevar» e incluso en algunos testimonios se incluía también la noción de «terrenos comunes de pasto y leña» a la salida del pueblo. Mucho después, relataba el diputado Dillón con relación a este tema:

Sobre uso de los ejidos en la época en que los pueblos eran zonas fronterizas: Yo no sé señor si en aquella época se hacía la distribución de los terrenos bajo determinadas leyes o reglamentos; pero a mí me consta y le consta a todas que al costado de esos pueblos se dejaba una cantidad de terreno para uso de la guarnición, para pastoreo de caballos o para sembrar en común los mismos milicianos que iban a dar la guardia allí32.

Puede vislumbrase entonces como a fines del siglo XVIII e incluso en los primeros años del siglo XIX, el concepto de «ejido» estaba aún ligado a la definición hispana que Joaquín Escriche sintetizó en su Diccionario de Legislación y Jurisprudencia: «tierras de uso común no cultivables a la salida de los poblados, del latín exitus que significa salida» ${ }^{33}$. Citemos solo un ejemplo: En 1798 se produjo un litigio en la Frontera de Luján (zona denominada posteriormente Guardia de Luján y ubicada al norte del Río Salado — ver mapa-) entre los labradores afincados allí y el propietario de esas tierras Don Pedro Díaz de Vivar. Dicho paraje comenzó a poblarse a mediados del siglo XVIII gracias a la creación del Fuerte La Valerosa y el establecimiento del Cuerpo de Blandengues que se ocupaba de defender la avanzada contra el indígena ${ }^{34}$. En el año citado se discutía entre los pobladores si parte de las

31 Aliata (París, 2010): en línea.

32 Diputados, Sesión del 28 de junio de 1865.

33 Escriche, 1851: 599. El Diccionario se editó por primera vez en 1831 en París. En México se editó en 1837 y 1843 . Luego tuvo varias ediciones corregidas y aumentadas. Entre 1847 y 1851 salió una nueva reimpresión que preparó originalmente Escriche, pero que fue terminada de componer por Juan M. Biec y José Vicente Caravantes. Las siguientes reproducciones tuvieron lugar en París en 1862 y 1869. En la imprenta de Eduardo Cuesta saldría una «Nueva edición reformada y considerablemente aumentada» entre 1874 y 1876 del Diccionario preparado por José Vicente y Caravantes y León Galindo y Vera. Todavía se reimprimió en Madrid en 1884 y en París en 1912. Lorén y Gómez, 1999: 115-129.

34 Tabossi, 1989. 
tierras de Díaz de Vivar constituía o no una Villa. Andrés Veloz, apoderado de los labradores, esgrimía los siguientes argumentos:

[...] porque ha llegado el caso de que aún pagando las pensiones establecidas, no se les deje parar allí y a otros aunque se les permite se les priva hasta el uso de la leña del campo, y de esta suerte un pueblo (el subrayado es nuestro) que poco ha sería floreciente y en estado de prometer la seguridad contra las irrupciones de los indios, a todos aquellos contornos, va caminando a su total desolación [...]

[...] se digne mandar, que ninguno de los pobladores, en la guardia de mi vecindario y cinco leguas en contorno, que lo menos se necesitan para sus pastos y eidos sea molestado con despojo arrendamientos ú otras pensiones por Díaz de Vivar o alguno para que en consecuencia pueda formarse el arreglo conveniente a una población tan útil y necesaria al Estado ${ }^{35}$.

En medio del proceso histórico de construcción de una nueva legislación sobre uso y función de los ejidos en Buenos Aires, la noción colonial se fue progresivamente distanciando de la postulada por Escriche puesto que fue adquiriendo características propias y particulares que terminaron diferenciándola tanto de la utilizada en España como en otras regiones de colonización española. Así, el concepto se amplió en la medida en que se incluyó a los «solares» y a las «tierras de labor» conjuntamente y se desvirtuó, al ser desprovisto de su carácter común ${ }^{36}$. Estas modificaciones no implicaron que, durante gran parte del siglo XIX, para cada una de las cuestiones referidas a los ejidos se acudiese al Derecho Indiano (sobre todo al Derecho de Castilla e incluso a las Partidas) como fuente de información permanente.

\section{La construcción de una legislación Para los ejidos de la Provincia Buenos Aires}

La ruptura del vínculo colonial generó en las regiones que integraban el Virreinato del Río de la Plata un sinnúmero de cambios, siendo los más significativos la orientación atlántica de la economía antaño vinculada al Alto Perú y la destrucción de riqueza producto de la guerra ${ }^{37}$. La orientación ganadera impulsada por la demanda de los países europeos brindó nuevas expectativas para las provincias del litoral, pero no todas pudieron vincularse del mismo modo. Buenos Aires surgió como la provincia que mejor se adap-

\footnotetext{
35 Fuente citada en Barcos, 14 (La Plata, 2007): en línea.

36 Barcos, 2009: 75-110.

37 Halperin Donghi, 1963. Amaral, 1993. Barsky y Gelman, 2001. Barsky y Djenderedjian, 2003.
} 
tó a los cambios tanto por el contexto político en el que estos se produjeron como por las propias características naturales de la región. Por eso, a partir de 1820 comenzó allí una expansión productiva sin precedentes basada en la ganadería extensiva, producto del progresivo vuelco de la inversión de los sectores mercantiles en la actividad primaria, que pudo efectivizarse con la apropiación de la tierra a las comunidades indígenas. A medida que la frontera se expandía y la estructura productiva se orientaba más decididamente hacia la ganadería, la agricultura colonial también se transformaba ya que el trigo iniciaba su peregrinaje desde los alrededores de Buenos Aires hacia el oeste y el sur de la provincia ${ }^{38}$. Paralelamente se creaban la mayoría de las guardias y fortines alrededor de los que se conformarían los pueblos de campaña, sus ejidos existían de hecho, pero solo unos pocos estaban trazados formalmente.

El primer antecedente en la materia fue una orden firmada en 1810 por el presidente de la primera Junta de Gobierno (Cornelio Saavedra) y Mariano Moreno en la cual se ordenaba visitar los fuertes para averiguar su estado y el de las poblaciones cercanas para encontrar la manera de reunirlos en pueblos. También se debía dar cuenta de la legitimidad con que se ocupaban los terrenos realengos e informar si los pueblos contenían ejidos. La inspección se realizó y para la tarea fue encomendado el citado Pedro Andrés García, pero las medidas no se aplicaron inmediatamente debido a que el gobierno estaba inmerso en los problemas ocasionados por el constante conflicto bélico. Nombrado Martín Rodríguez como gobernador de Buenos Aires ordenó en abril de 1822 la prohibición de vender, denunciar y expedir títulos de propiedad fiscal. A partir de esta fecha, las tierras dejaron de transferirse en propiedad y comenzaron a darse en usufructo bajo el sistema de enfiteusis ${ }^{39}$.

Durante el periodo rivadaviano comenzaron a llevarse a la práctica algunas de las ideas postuladas por Pedro Andrés García. En 1823 se ordenó la traza de los pueblos de campaña: una vez levantado el plano se reservaría una legua en circunferencia para la agricultura, medida que fue reemplazada posteriormente por cuatro leguas cuadradas (10.800 has), este espacio se declaraba «de pan llevar» prohibiéndose el pastoreo ${ }^{40}$. En 1825 se estableció que los terrenos sitos dentro de estas áreas no se darían en enfiteusis debido a los males que podía acarrear entregar bajo este sistema las tierras acordadas para agricultu-

38 Djenderedjian, 2008: 26.

39 Desde 1824 el Estado utilizó su patrimonio en tierras como garantía de la deuda pública contraída mediante el Empréstito Baring. Amaral, XXIII/ 92 (Buenos Aires, 1984): 551-588.

40 Decreto del 16 de abril de 1823. Muzlera, s/f: 26-27. 
ra. Sin embargo, al año siguiente las tierras fueron incluidas bajo el mismo régimen ${ }^{41}$. Las comisiones de solares fueron facultadas para otorgar en enfiteusis las quintas y chacras de la parte baldía de los ejidos, en cambio, para los situados en la línea de frontera se ordenó que fueran los comandantes militares los que procedieran a distribuir en donación las parcelas entre los pobladores. Durante el primer gobierno de Juan M. de Rosas (1829-1832) la política de donaciones continuó pero además se envió una comisión para averiguar la situación y extensión de los terrenos de labranza, las tierras que se encontraren vacantes debían darse en arrendamiento. También en estos años se aprobó la traza de varios pueblos y ejidos. En cuanto a los fundados más allá de la línea de frontera, se aumentó la superficie destinada para ejido de cuatro a cinco leguas y se acordó donar las parcelas.

La política de donaciones que implementaron los gobiernos de Buenos Aires como modo de fomentar la población fue una idea que estaba presente en la legislación indiana. En los apartados referidos a población reunidos en la Recopilación se establecen dichos criterios. Por ejemplo: «Repartanse los folares por fuertes á los pobladores, continuando desde los que corresponden á la plaza mayor, y los demás queden para nos hacer merced de ellos á los que de nuevo fueren á poblar, ó lo que fuere nuestra voluntad» ${ }^{42}$. También:

Haviendo Señalado competente cantidad de tierra para exido de la población [...] y loreftare en tierras de labor, de que hagan fuertes, y fean tantas como los solares, que puede haver en la población, y fi hivere tierras de regadío, afsimisfmo fe hagan fuertes, y repartan en la mifma proporción á los primeros pobladores, y las demásqueden valdias, para que Nos hagamos mercedes á los que de nuevo fueren ápoblar:y de eftas Tierras hagan los Virreyes feparar las que parecieren convenientes para propios de los pueblos, que no los tuvieren, de que fe ayude á la paga de falarios de los Corregidores, dexando exidos, deheffas, y paftos baftantes, como efta proveido, y afsi lo executen ${ }^{43}$.

Por supuesto que en el planteo indiano, como ya explicamos, las tierras de labor no estaban en los ejidos, pero el concepto de donación es el mismo. También la obligación de poblar y edificar que establecieron todos los decretos y leyes sobre ejidos en Buenos Aires y la obligación de permanecer en los terrenos otorgados con cultivo se inspiraron en las leyes del Título VII del Libro IV de la Recopilación.

41 Otorgándose la concesión por 10 años y pagando un canon del 4\% Decreto del 24 de octubre de 1825, Muzlera, s/f: 45. En julio de 1828 se dictó finalmente la ley de enfiteusis para tierras de pan llevar que estipulaba lo mismo que el decreto anterior pero bajaba el canon al $2 \%$.

42 Recopilación, L. IV. Tít. VII. Ley XI.

43 Ibidem, Ley, XIV. 
A partir de 1840, producto del contexto políticamente álgido por el que atravesaba la provincia y hasta 1852, la Cámara de Representantes no sancionó leyes sobre tierras públicas ni se realizaron trámites de escrituración ${ }^{44}$. Promediando el siglo, la caída del gobernador Rosas propició una nueva coyuntura política mientras que Buenos Aires experimentaba un impulso económico importante producto de su inclusión en el comercio internacional como proveedora de lana sucia. Esta reorientación productiva propició, sobre todo en los partidos del norte, un movimiento migratorio de pastores europeos especializados en dicha actividad ${ }^{45}$. La política general en torno a las tierras públicas y el fomento del ferrocarril acompañaron este proceso apoyando la actividad ganadera exportadora. En este contexto, se instauraba entre los legisladores la conveniencia de pasar gradualmente a un sistema que entregara definitivamente la tierra en propiedad. En la campaña, la ley de venta de tierras al interior del Río Salado de 1857 inauguró el proceso, en cuanto a los ejidos; en 1858 se sancionó la primera ley de venta ${ }^{46}$. Este proceso «modernizador» no fue exclusivo de esta región puesto que desde mediados del siglo XIX se sancionaron tanto en España como en América un conjunto de medidas desamortizadoras que tuvieron como denominador común la venta de terrenos públicos y comunales (incluidos los ejidos), la desvinculación de señoríos y la desamortización de bienes de la Iglesia ${ }^{4}$.

Entre los legisladores del periodo, la posibilidad de que las ventas de terrenos ejidales generaran importantes ingresos al erario público no creaba fuertes expectativas ya que se temía que los ocupantes no se presentaran a comprar y que los litigios fuesen interminables. Así sucedió, la disposición sancionada en 1858 generó varias cuestiones entre las municipalidades y los pobladores sobre cuáles eran los terrenos públicos de los que se hablaba, quiénes debían comprar y cómo avalaban el tiempo de posesión los actuales ocupantes. Debido a esto, en 1862 se sancionó una ley que reconocía la propiedad a los poseedores de suertes de quintas y chacras anteriores al decreto del 17 de abril de 1822 (que prohibía la venta de tierras públicas)48. Esta normativa tenía como objetivo contemplar la multiplicidad de variantes en las que se encontraban los poseedores. Si bien no suplantaba la ley de venta, la complementaba incluyendo los casos de antigua posesión. Según las áreas y los años de ocupación se estipulaba: el reconocimiento en propiedad (a título

\footnotetext{
44 Infesta y Valencia, II (Tandil, 1987): 177-213.

45 Valencia, 2005. Sabato y Korol, 1981.

46 Ley del 4 de octubre de 1858. Muzlera, s/f: 211-212.

47 Menegus y Cerruti, 2001.

48 Ley del 7 de octubre de 1862. Muzlera, s/f: 42-44.
} 
de dominio), el beneficio de pagar la mitad del valor de la tierra (reconocimiento parcial), la donación en la frontera y la venta. Sin embargo, esta ley no terminó de resolver todas las cuestiones: el problema mayor radicaba en los casos de antiguos pobladores que habían recibido donaciones de parte del comandante militar o de la comisión de solares antes de 1822. Esta cuestión generó acalorados debates y varias leyes modificatorias debido a la multiplicidad de formas en que se otorgaron las parcelas ejidales y las diferentes interpretaciones que se hacían en las cámaras de los términos título, ocupante, dominio, propiedad y reconocimiento. Producto de ello, en 1867 Nicolás Avellaneda se propuso trabajar en la confección de una ley general de ejidos que intentara dar reglas comunes para facilitar la venta de las parcelas. La nueva ley fue sancionada en 1870 cerrando un ciclo en cuanto a las políticas de fomento de población y cultivo en espacios reducidos como los ejidos.

Antes de analizar los debates, pretendemos hacer algunas aclaraciones en torno a cómo se fue implementando la legislación en la provincia. Como ya esbozamos, un análisis general sobre el modo en que se surgieron los ejidos en la campaña de Buenos Aires permite advertir que su creación estuvo íntimamente relacionada con el fomento del pueblo al cual debían rodear. Y en este sentido, existieron desde la colonia diversas motivaciones además de la oficial para el surgimiento de poblados. Así, de acuerdo a las regiones que se estudien y el periodo las tipologías varían como así también el impacto de la legislación que hemos referenciado. Tal diversidad implica considerar cada caso por separado, pero dicha tarea excede el marco propuesto para este artículo ${ }^{49}$. No obstante, para nuestro propósito específico pueden aislarse algunas cuestiones que sirven de marco de referencia general. Así, podemos listar los siguientes factores como «incentivadores» de la constitución de centros poblados: la iniciativa de los particulares basada en intereses propios, la presión de los pobladores por contar con entidad jurídica de pueblo para poder designar sus propios representantes, la intervención de la iglesia, la creación de reducciones, el establecimiento de fuertes y, en la segunda mitad del siglo XIX, la extensión de las vías férreas.

En cuanto a sus ejidos, muchos de los más antiguos (ubicados al norte del Río Salado - ver mapa-) existían de hecho como zona de pastos y agricultura indistintamente $\mathrm{y}$, en algunos casos, se trazaron conforme la normativa colonial. Como se deduce de la legislación analizada anteriormente, las trazas formales comenzaron posteriormente puesto que los organismos encargados de dicha tarea se crearon a partir de la década de 1820 (Departamento de

49 Para el caso de los ejidos de los partidos de la Guardia de Luján y de Monte, Barcos, 2007 y 2010. 
Ingenieros, Comisión Topográfica, Departamento Topográfico). Dichas entidades fueron las encargadas de llevar a la práctica el conjunto de medidas destinadas a reconocer el territorio (ubicación, extensión, uso y calidad del suelo, accidentes, etc.) para la construcción de un catastro provincial que pudiera utilizarse, entre otras cosas, con un criterio fiscal. En la mayoría de los casos, los terrenos en los que se debían trazar los ejidos ya estaban ocupados por labradores y por eso los agrimensores tuvieron serias dificultades para el reordenamiento. Cuando los terrenos estaban ocupados por estancias, la ley pautaba la expropiación y posterior permuta. No obstante, la rigurosidad en las tareas encomendadas parece haber sido bastante limitada puesto que la efectividad de las permutas no se dio en todos los casos ni se efectuaron todas las mensuras de las unidades productivas (quintas y chacras). Por eso muchos planos ejidales se confeccionaron nuevamente cuando comenzó el ordenamiento legislativo en función de la puesta en venta de los terrenos públicos sitos en los ejidos que ya explicamos. No obstante lo expuesto, se realizaron también trazas planificadas de antemano, sobre todo luego de la década de 1860, al calor de la expansión del ferrocarril y el avance de la frontera. Por último, existieron casos donde los ejidos fueron directamente trasladados de una zona a otra dentro del partido.

Así, la implementación técnica de los proyectos fue diversa, tanto en relación con la superficie que los ejidos abarcaban (que por ley era de cuatro leguas cuadradas) como por los tipos de planos que se confeccionaron y los terrenos que se expropiaron para las trazas. Algunas de las tierras utilizadas para ejidos eran fiscales, otras eran porciones de terrenos particulares que tuvieron que permutarse e incluso también existieron casos de terrenos que pertenecían a la Iglesia y que con la creación de las municipalidades (1854) entraron en disputa. En el transcurso de este intrincado proceso, los sucesivos gobiernos de Buenos Aires tuvieron que conciliar (con resultados diversos) los conflictos que, en varios planos simultáneos y superpuestos, el ordenamiento territorial generaba: labradores contra estancieros, entre los labradores y las instituciones locales y entre las instituciones entre sí. Asimismo el gobierno debió valerse de organizaciones locales de poco nivel de formalización (las Comisiones de Solares) que actuaron de intermediarias - junto con los Jueces de Paz- entre el gobierno y las comunidades locales por lo menos hasta la creación de las Municipalidades. Dichas comisiones se convirtieron en organismos centrales de poder en los pueblos puesto que decidían a quién otorgar tierras (donaciones), la superficie que se adjudicaba (amparar mayor superficie que la estipulada) y, en los casos en que existían disputas, qué solicitudes sobre «mejor derecho» avalar. 
El DileMA DE LA PROPIEDAD EN LOS DEBATES PARLAMENTARIOS SOBRE LA LEGISLACIÓN EJIDAL EN EL PERIOdo DE TRANSICIÓN A LA ARgENTINA ModERnA

Triste cosa sería, que nosotros, republicanos como somos hubiésemos de dar leyes peores que las que el rey de España, absoluto, daba para estos casos.

Senador Estévez Seguí, 1 de agosto de 1865

Volviendo específicamente al influjo del Derecho, a mediados del siglo XIX las tensiones en la legislación y en las prácticas reaparecen muy claramente denotando que el tránsito hacia las nuevas concepciones en torno a la propiedad fue más dificultosa de lo que la historiografía tradicionalmente postuló. Así, si bien el afianzamiento y clarificación de los derechos de propiedad que se operó a partir de mediados del siglo XIX significó el paulatino triunfo de un modo específico de entender la propiedad (individual y posesorio), este proceso no fue simple ni rápido ${ }^{50}$. Convivieron hasta bien entrado el siglo XIX diferentes concepciones de la propiedad y diferentes maneras de ser propietario. Como pudimos observar, el derecho indiano prevaleció en América aún después del proceso revolucionario; historiadores del Derecho han puesto énfasis en la persistencia de esta cultura jurídica hasta el tardío proceso de codificación cuando menos ${ }^{51}$. A su vez, la costumbre adquirió fuerza jurídica toda vez que se introdujo en los requisitos de ese derecho. Por ello, el proceso codificador no estuvo exento de tensiones que se manifestaron muy claramente en tres momentos: a fines del siglo XVIII, en la segunda década del siglo XIX y a partir de $1850^{52}$.

Como señalamos al inicio de este artículo, una de las primeras cuestiones que puso de manifiesto el análisis de la legislación es la continuidad normativa con el pasado colonial, sobre todo en materia de tierras ejidales. Si nos atenemos ahora específicamente a la cuestión de la propiedad, observamos un proceso sinuoso puesto que los labradores tenían nociones impregnadas desde antaño sobre qué fundaba la propiedad y las pusieron de manifiesto cada vez que necesitaron fundamentar sus derechos. Estas concepciones aprehendidas a través de los años llevaban implícitas los fundamentos indianos más tradicionales. Al mismo tiempo, las ideas ilustradas tuvieron eco en el Río de la

50 Citando a Grossí, 1992: 32, «se cristalizó en el siglo XIX un singular arquetipo jurídico, que podemos calificar napoleónico-pandectístico, es decir una noción de propiedad resuelta no sólo en la apropiación individual sino en una apropiación de contenidos potestativos».

51 Tau Anzoategui, 1987. Díaz Couselo, 7 (Buenos Aires, 2005): 45-74.

52 Fradkin, 12 (Tandil, 1997): 141-156. 
Plata, pero mediatizadas por los pensadores de la época, los cuales no se habían desprendido aún de principios mercantilistas.

Desde lo teórico, Pedro Somellera consideraba sinónimos: dominio y propiedad ya que en el origen de la propiedad se distinguía tanto la tradición como la ley aunque finalmente terminó otorgando mayores atributos a la ley. Esta concepción de la propiedad estaba presente también en Joaquín Escriche ${ }^{53}$ para quien la propiedad era «El derecho de gozar y disponer libremente de nuestras cosas, en cuanto las leyes no se opongan». Y tenía dos acepciones ya que expresaba tanto el derecho en sí mismo, el dominio, como la cosa en que se tenía ese derecho ${ }^{54}$. La supremacía de la ley venía dada porque para el autor la propiedad era obra del derecho civil. Antes del establecimiento de las leyes no existía garantía de la propiedad ya que el dominio sobre la cosa (derecho) solo se preservaba mediante la posesión (hecho). La ley permitió luego desvincular la propiedad (derecho) de la posesión y así: «[...] un individuo pudo ser propietario sin poseer la cosa y poseerla sin ser propietario» ${ }^{55}$. En definitiva, la propiedad aparece como un vínculo que la ley fija entre la cosa y el sujeto que ejerce el derecho sobre esa misma cosa. Según la relación que se establezca se la define como perfecta o imperfecta. En el primer caso, el vínculo no está dividido y no existe ningún derecho que limite el ejercicio del derecho de propiedad. Cuando esto sí sucede la propiedad es imperfecta. Pero, como explica Rosa Congost ${ }^{56}$, en ningún momento Escriche definió la propiedad en términos evolutivos: imperfecta-feudal y perfecta-moderna.

Como propiedad sería originalmente dominio veamos el significado del término. Escriche diferencia dominio pleno: «El poder que uno tiene en alguna cosa para enajenarla sin dependencia de otro, percibir todos sus frutos, y excluir de su uso a los demás» y menos pleno. Este último se subdivide en:

Directo: El derecho que uno tiene de concurrir a la disposición de una cosa cuya utilidad ha cedido, o de percibir cierta pensión o tributo anual en reconocimiento de su señorío o superioridad sobre un fundo, o bien el derecho de superioridad sobre una cosa raíz sin el derecho de la propiedad útil. Tal es el dominio que se ha reservado el propietario de una finca enajenándola solo a título de feudo o enfiteusis. Útil: es el derecho de percibir todo los frutos bajo alguna prestación o tributo que se paga al que conserva en ella el dominio directo. Tal es el dominio que tiene el vasallo o enfiteuta en la heredad que ha tomado a feudo o enfiteusis ${ }^{57}$.

\footnotetext{
53 Escriche, 1851: 1392.

54 Idem.

55 Escriche, 1851: 1393.

56 Congost, 2007: 142.

57 Escriche, 1851: 568.
} 
Estas definiciones son clave para comprender desde qué concepciones se legisló en materia ejidal teniendo en cuenta, no obstante, que estas nociones se aplicaron a un contexto que no era el europeo y debido a ello resultó más compleja aún su interpretación; sobre todo a partir de la segunda mitad del siglo XIX, cuando se quiso uniformar, haciendo tabla rasa, el concepto de propiedad. Los problemas surgieron tanto a nivel teórico como práctico porque el otorgamiento de tierras en la primera mitad del siglo XIX no había implicado la propiedad perfecta definida en los términos de Escriche. A partir de 1822 la tierra que se ganaba al indígena se declaraba de propiedad pública (durante la colonia se declaraban realengas) y la titularidad recaía en el Estado, quien la otorgaba de diferentes maneras. En el caso de las tierras ejidales, las modalidades fueron donación, enfiteusis y arrendamiento. En los últimos dos casos el estado retenía el dominio directo y cedía el dominio útil a cambio de un canon. El caso de las donaciones ejidales es más complejo a partir de 1823: «el estado retenía el dominio directo pero donaba el dominio útil» no percibiendo retribución alguna por la cesión. Mientras en los primeros dos casos la posesión no generaba derechos, en el caso de las donaciones el poblador poseía «a título propio» (a titulo de dominio) y por eso la permanencia continuada le permitía con el tiempo reclamar la propiedad (derecho).

El intento de ordenamiento que proyectó construir un cuerpo normativo uniforme sobre la propiedad, la familia y la herencia quedó plasmado en los códigos y en el conjunto de leyes del periodo ${ }^{58}$. Para los ejidos, la ley de 1858 inauguró el proceso poniendo en venta los terrenos para quintas y chacras, pero esta normativa no contemplaba el concepto de propiedad dividida presente en las leyes anteriores, lo que en la práctica implicó desconocer la propiedad de los antiguos pobladores. La solución llegó más tarde y solo cuando los pobladores se negaron a presentarse ante el gobierno, mediante la figura del reconocimiento a título de dominio. Esta amparaba el derecho a obtener un título sobre la tierra poseída por más de 40 años. A través de este mecanismo se subsumió la diferencia entre posesión/propiedad vigente durante años. Los pobladores reconocidos debían escriturar sus tierras como propietarios plenos y absolutos, reuniendo en sus manos tanto el derecho como el título que reconoce ese derecho.

Los debates suscitados en las Cámaras de Senadores y Diputados son muy ricos para analizar esta cuestión debido a que en el transcurso de las sesiones los legisladores expusieron las dificultades que presentaba el tema y cómo se recurría constantemente al Derecho Indiano para aclarar situaciones. Veamos

58 Zeberio, 9 (La Pampa, 2005/2006): 151-183. 
algunos ejemplos relacionados con lo que venimos exponiendo. En agosto de 1865 se debatía en Senadores un nuevo proyecto de ley que intentaba resolver las confusiones que habían generado las diferentes interpretaciones de la legislación sobre ejidos. La discusión fundamental durante ese año giró en torno a un nuevo proyecto que modificaba nuevamente la forma en la cual los tenedores de tierras ejidales debían justificar la posesión para escriturar sus tenencias. La ley de 1862 acordaba el reconocimiento de la propiedad a los poseedores anteriores a 1822 con título o sin él pero en 1864 , cuando se reglamentó, se decretó que los poseedores anteriores a 1822 «tenían que justificar» para ser reconocidos como propietarios que ellos o sus sucesores se habían mantenido «ininterrumpidamente» en el terreno con cultivo o población hasta 1862. Para tal efecto debían brindar un interrogatorio ${ }^{59}$.

En 1865 se sancionó una nueva ley que establecía en su artículo $3 .^{\circ}$ : «Se declara que basta el hecho de posesión con población o cultivo para optar a la escrituración, siempre que no se pruebe haber sido a nombre del Estado o de cualquier otra persona». Aquí la posesión no necesariamente debía ser a título de dominio y se extendía a todos los pobladores de tierras ejidales siempre que no fueran enfiteutas o arrendatarios. Este artículo había sido introducido por Diputados y la discusión se generó cuando volvió el proyecto a Senadores. El primero en oponerse fue el Ministro Castro, quien inició una acalorada discusión sobre la palabra y el sentido del término «título»:

La palabra título, como saben todos, se toma por el derecho con que posee uno una cosa, pero también por el documento mismo, y es en este sentido que se dictó el decreto del año 22. A pesar de lo que él dispuso, siguieron los Comandantes y Jueces de Paz haciendo concesiones de estos terrenos y los que recibían estas concesiones se creyeron con títulos bastantes para adquirir la propiedad, aunque no se les había dado escritura ${ }^{60}$.

Con estas palabras nos introducimos en el foco de nuestra problemática: ¿quiénes tenían derecho a ser reconocidos como propietarios? y ¿cómo se adquiría la propiedad? En sus palabras están claramente especificadas las posturas que veníamos analizando y que convivieron en nuestra legislación de manera no siempre armoniosa. Por un lado, la propiedad fundada en el derecho positivo que indicaba que la Ley es la fuente del derecho. En este sentido se entendía por título suficiente y valedero al documento emanado por

59 Decreto del 1 de julio de 1864, Muzlera, s/f: 94-96.

60 Diario de sesiones de la Cámara de Senadores de la Provincia de Buenos Aires (en adelante Senadores). Sesión del 1. ${ }^{\circ}$ de julio de 1865: 84. 
la autoridad vigente. Por otra parte, la que postulada que la propiedad se fundaba en la antigüedad de la ocupación y el dominio útil sobre la cosa:

Los poseedores anteriormente decían: este terreno es mío porque se me ha repartido a mí con condición de poblarlo, y lo he poblado. La Municipalidad decía: muéstreme usted sus títulos. No había títulos porque generalmente todos esos repartos se hacían por los comandantes de frontera [...] No tenían, pues, ninguna constancia por escrito de los títulos; no tenían más que 40 años de posesión continuados ${ }^{61}$.

Aquí encontramos aprehendida en términos de mentalidad nociones que concebían la propiedad en el uso, la costumbre y el fuero. Conviene, no obstante, no considerar en todos los casos las nociones de los legisladores letrados y la población rural en términos dicotómicos. Tampoco suponer consenso doctrinario en el seno mismo de los legisladores. En el debate que analizamos, los mismos legisladores apoyaban o rechazaban esta ley desde concepciones de la propiedad diferentes. Por ejemplo, Castro y Tejedor insistían en que no es lo mismo poseedores (ocupantes) que poseedores a título de dominio ya que a estos últimos la tierra les fue otorgada por los comandantes, las comisiones de solares o el juez de paz mediante un documento. No importaba si al momento de escriturar contaban o no con este papel (porque podían avalar la posesión mediante un interrogatorio), pero lo importante era que quien les había otorgado la tierra actuaba como representante del Estado y operaba conforme a una ley; nuevamente Somellera. En 1868 encontramos otra definición de lo que significaba el título de dominio en palabras del Diputado Moreno: «[...] la posesión que da derecho a la propiedad o a ser reconocido como dueño» ${ }^{62}$. En otras palabras, era la posesión a nombre propio que se diferenciaba de la que detentaba el inquilino, enfiteuta o usufructuario que poseían, pero no poseían como dueños ya que al pagar un canon reconocían la propiedad en otro. Estévez Seguí defendía el artículo remitiéndose a las Leyes de Indias para avalar sus argumentos. Citaba la Ordenanza de 1754 que ya hemos analizado en la primera parte del trabajo, esta establecía que «[...] baste la posesión como justo título». Expresaba Seguí:

Lo que se trata de hacer, quitando de la ley el artículo 3, es precisamente ir contra la liberalidad de esas leyes, que sería vergüenza nuestra no sostenerlas, quizás porque son de un rey absoluto. Se tienen las leyes de Indias expresas: se tiene una ordenanza de 15 de octubre de 1754: pues bien señor, ese rey absoluto decía, baste la posesión como justo título, para que tal terreno haya dejado de ser realengo. Esto decía el rey de España a sus colonos; y nosotros republicanos, vamos a decir

\footnotetext{
61 Senadores, sesión del 23 de septiembre de 1862.

62 Ibidem, sesión del 10 de junio de 1868: 139.
} 
a esos infelices que están poblados en los ejidos de los pueblos de campaña, es una ilusión: la tierra es de todos, si, pero si la habéis poblado, es porque convenía poblarla; ya lo está: mientras se formaba el pueblo; mientras que teníamos que luchar con todos los inconvenientes anexos a los principios, pudimos conservar la esperanza: mas ahora esa tierra vale mucho; es preciso que la paguéis bien ${ }^{63}$.

Agrelo consideraba que los poseedores anteriores a 1822 debían ser escriturados «[...] proceda de donde proceda la posesión». Este senador atacaba el título de dominio e invocaba el criterio de la prescripción (que luego fue introducido como ley referente a los ejidos en 1867): «[...] la ley de Indias viene a reconocer y revalidar el derecho que las de Partida habían establecido sobre la prescripción contra el físco». Carlos Tejedor se oponía al artículo ya que consideraba que al suprimir la justificación de la posesión se daría lugar a los intrusos, pero Agrelo replicaba: «Hay una diferencia inmensa entre probar el derecho adquirido, porque probar derechos es muy difícil, y en demostrar el hecho material de la posesión que es muy fácil».

Algunos de los senadores conocían mejor las leyes ejidales que otros; sin embargo, todos coincidían en lo complicado que resultaba el tema. Tejedor y Castro por un lado y Agrelo por otro manejaban mejor información sobre la cuestión de tierras que el resto de los senadores y eso se nota en sus intervenciones. Por ejemplo, Tejedor exponía claramente el problema:

En la discusión han quedado evidentes dos puntos, Primero que si por la disposición de la Cámara de Diputados se ha querido solamente garantizar a los poseedores a título de dominio, esa garantía la tiene ya por la ley del año 62, por la práctica y juridisprudencia del Tribunal de Justicia, y por consiguiente, la disposición no necesita reformarse ni confirmarse; segundo, que si por ella se ha querido introducir el principio de la prescripción de la tierra pública, no es este el modo de hacerlo, a hurtadillas, ni sería tampoco conveniente, para la riqueza pública en general, ni para la de los municipios en particular ${ }^{64}$.

Finalmente la ley fue aprobada por ocho votos contra siete tal como había sido enmendada por Diputados pero, como todas las leyes ejidales, tuvo poca vida: el 10 de octubre del mismo año se sancionó otra ley que derogó el artículo $3 .^{\circ}$ motivo del debate. En esa oportunidad se convocó a Asamblea debido a que el Poder Ejecutivo solicitó vetar el proyecto dos días después de sancionado. Argumentaba que la promulgación del artículo $3 .^{\circ}$ implicaba sostener que el Poder Ejecutivo y el Poder Judicial, al exigir la posesión a título de dominio, habían malinterpretado el espíritu de la ley de 1862. Son interesantes las palabras del Sr. Quintana al respecto:

63 Senadores, sesión del 1 de agosto de 1865: 86.

64 Ibidem, sesión del 10 de octubre de 1865: XII. 
Más de once años tiene de dictada la Constitución de la Provincia, y hasta ahora la voz del ejecutivo no se había hecho escuchar por razón de un veto, y durante es largo periodo se han dictado leyes de la mayor importancia que no han estado conformes con las ideas y proyectos del Poder Ejecutivo, y este se ha guardado bien de observar esas resoluciones [...] es de estrañarse que con un proyecto de tan poca importancia, que no tiene otro fin que interpretar una ley, el Poder Ejecutivo haya hecho uso de la peligrosa facultad del veto ${ }^{65}$.

El Ejecutivo actuaba de esa manera porque el problema no eran solo los ejidos de los pueblos sino el antecedente que esto podría generar en la legislación sobre tierras públicas. Carlos Tejedor lo manifestaba de manera explícita:

[...] si este artículo triunfa, y con él, por consiguiente, dicho principio (el de la prescripción), el será llevado más tarde a toda la tierra pública del Estado, y no se aplicará solamente a las pequeñas fracciones de terrenos de los egidos, sino a terrenos de pastoreo. Calcule, pues, la asamblea cuales serán las consecuencias del articulo $[\ldots]^{66}$.

Finalmente no se obtuvieron las dos terceras partes necesarias para mantener el artículo y este fue derogado. Al año siguiente se sancionó aparte la ley que incorporaba la figura de la prescripción para los terrenos de los ejidos, pero también con un acalorado debate puesto no quedaban claros los alcances de la prescripción. El diputado González esgrimía:

Las leyes españolas que actualmente nos rigen, copiando a los romanos, han consagrado también ese mismo principio a las antiguas posesiones. Así vemos en la partida $2 .^{\circ}$ que la ley 21 , tít. 29 , confiere dominio al que ha ocupado una cosa raíz privada durante treinta o más años continuos, autorizándolo a no responder a la demanda que le pusiera su propietario ya sea que la posesión haya sido con buena o mala fe. Y así como nuestra legislación ha establecido la prescripción respecto de las cosas raíces privadas, se ha extendido también a los bienes inmuebles públicos, que no están destinados al uso común. A este respecto tenemos la disposición de la ley 7 , tít., 29 , partida $3 .^{\circ}$ que establece la prescripción de esos bienes públicos no destinados al uso común, fijando solo a la posesión el plazo de 40 años continuos ${ }^{67}$.

Expresaba que con esta ley se buscaba el «espíritu» de las de Partida, pero luego aclaraba la «innovación» de la novata legislación:

La única innovación que este proyecto introduce en nuestra actual legislación, es suprimir los cuatro años que por la mencionada ley 7 se conceden al Fisco o a las
65 Idem.
66 Idem.
67 Diputados, sesión del 28 de junio de 1867. 


\begin{abstract}
Municipalidades para poder pedir todavía que el tiempo corrido durante los largos cuarenta años, no les perjudicasen; lo que solo puede explicarse, como un resto de esos odiosos privilegios, que las leyes de la monarquía otorgaban a tales personalidades, y que es necesario vayan desapareciendo, si es que queremos hacer prácticas las instituciones que nos rigen ${ }^{68}$.
\end{abstract}

Es interesante como González plantea que las leyes coloniales «están» en vigor y luego habla de «nuestra» legislación. Claramente en torno a lo normativo aún se estaba en un proceso de transición en el que el derecho positivo ocupaba un lugar bastante marginal, pero aún así se proclamaba la modernidad respecto de las instituciones españolas. Finalmente la ley se promulgó diferenciando la propiedad particular de la pública y de esta solo se estableció prescripción para los terrenos que no fueran de uso común o institucional. Así: «la posesión continuada por cuarenta años conforma suficiente título de propiedad contra el dominio del fisco o las municipalidades».

En 1870 se sancionó finalmente la Ley General de Ejidos que refundió parte de las disposiciones vigentes. En cuanto a poseedores por 40 o más años continuados fue suprimida la figura del título de dominio y se ratificó la prescripción con la mera ocupación a nombre propio. Esto implicó extender la categoría de ocupante factible de ser reconocido como propietario a todo poblador que poseyera a nombre propio. Esto obedeció también a la propia incongruencia entre las normas y las prácticas: los poseedores posteriores a 1822 habían obtenido también sus tierras por parte de las autoridades, pero en un momento en que ya estaba vigente la prohibición de otorgar la propiedad. El agraciado de 1821 no diferenciaba su tenencia del agraciado de 1823 aunque jurídicamente estas adjudicaciones eran diferentes. Los pobladores no conocían las sutilezas de la legislación ni sabían que lo que se otorgaba luego de 1822 no era la propiedad sino la acción. Así:

La creencia de dueño y la naturaleza del título de que nace ese derecho lo hacen acreedor a esa consideración: aun cuando el Juez de Paz nunca haya tenido derecho de enajenar la tierra pública, la ley, por traspasarla del dominio público al privado le reconoce este dominio ${ }^{69}$.

En suma, la complejidad de la legislación y la multiplicidad de concepciones de la propiedad que hemos señalado son evidentes y denotan la imposibilidad de hablar en términos jurídicos de «propiedad perfecta» en el periodo que nos ocupa.

\footnotetext{
68 Diputados, sesión del 28 de junio de 1867.

69 Ibidem, sesión del 10 de junio de 1868: 141.
} 
A MODO DE CONCLUSIÓN

A lo largo de este trabajo se pudo demostrar cómo la construcción de un cuerpo normativo para los ejidos fue un proceso lento, dificultoso y no exento de conflictos en el que la influencia del Derecho Indiano en sentido amplio fue nodal. Las normativas sobre pueblos, poblaciones y ejidos adaptaron las normas indianas, que originalmente tuvieron en cuenta otros espacios de más antigua colonización (sobre todo Nueva España), a la realidad específica de Buenos Aires en un conjunto heterogéneo de disposiciones sueltas que solo encontraron carácter definitorio con la sanción de la Ley General de Ejidos de 1870. En primer lugar, el significado del término ejido varió respecto del sentido tradicional que tenía en las Leyes de Indias puesto que se denominó así a la superficie de tierra parcelada y de usufructo individual que rodeaba a los pueblos de campaña destinada a establecer exclusivamente población y cultivo en unidades denominadas solares, quintas y chacras. No obstante esto, en la práctica los labradores muchas veces utilizaban el termino para referirse a los terrenos comunes de pasto y leña.

En segundo lugar, los proyectos de raigambre colonial sobre agricultura y fundación de pueblos que Pedro Andrés García expresaba en sus informes representan el tránsito entre dos modos de comprender los ejidos, no obstante estos se fueron concretando paulatinamente a través de la legislación independiente de modo sui generis. El conocimiento actual sobre la formación de pueblos y ejidos en la de la campaña bonaerense demuestra la multiplicidad de motivaciones que impulsaron dichas trazas, la variabilidad de formas de efectuarlas como así también los conflictos que se generaron en el seno de las comunidades locales donde el embrionario poder gubernamental tuvo que mediar entre intereses encontrados.

A partir de 1810, momento en el cual se inició lentamente el proceso revolucionario que derivaría en la independencia de la región de España, se comenzó a pensar sistemáticamente en proyectos de colonización y en otorgar un ordenamiento territorial a la campaña de Buenos Aires. Para eso se comenzó a proyectar la traza de los ejidos y se inició el proceso de construcción de una legislación propia e independiente para estos espacios. Esto significó en la práctica adaptar las disposiciones de raigambre colonial sobre pueblos, poblaciones y ejidos conforme cada coyuntura, generando un conjunto complejo y heterogéneo de disposiciones cuya inspiración más genuina fue el Derecho Indiano y que, a mediados del siglo XIX, entraron en tensión con el movimiento codificador liberal, puesto en práctica de modo cada vez más enfático. 


\section{BiBLIOGRAFÍA}

Aliata, Fernando, «Cultura urbana y organización del territorio», Goldmann, Noemí (comp.), Nueva Historia Argentina, Buenos Aires, Sudamericana, 1998, tomo III: 199-248.

Aliata, Fernando, «Las raíces del árbol de la libertad. El legado ilustrado en la fundación de pueblos en la pampa bonaerense durante el siglo XIX», Nuevo Mundo Mundos Nuevos, Debates [en línea], 2010.

Amaral, Samuel, «Del mercantilismo a la libertad: las consecuencias económicas de la independencia argentina», Prados de la Escosura, Leandro y Amaral, Samuel (eds.), La independencia americana: consecuencias económica, Madrid, Alianza Editorial, 1993: 210-218.

Amaral, Samuel, «El empréstito de Londres de 1824», Desarrollo Económico, 92/23 (enero-marzo, Buenos Aires, 1984): 551-588.

Barcos, María Fernanda, «Los ejidos de los pueblos de campaña: ocupación y acceso a la propiedad legal en Monte, 1829-1865», Mundo Agrario, 14 (La Plata, 2007), en línea.

Barcos, María Fernanda, «Los intersticios de la ley. De la sanción a la implementación de la legislación ejidal en Mercedes», Banzato, Guillermo y Blanco, Graciela (comps.), La cuestión de la Tierra Pública en Argentina. A 90 años de la obra de Miguel Ángel Cárcano, Rosario, Prohistoria Ediciones, 2009.

Barcos, María Fernanda, De cada labrador un soldado y de cada agricultor un propietario. Economía, sociedad y política en el ejido de la Guardia de Luján (Mercedes), 1810-1870. Tesis doctoral inédita, Argentina, Universidad Nacional de La Plata, 2010.

Barsky, Osvaldo y Djenderedjian, Julio, Historia del capitalismo agrario pampeano. Tomo 1, La expansión ganadera hasta 1895, Buenos Aires, Universidad de Belgrano-Siglo XXI, 2003.

Barsky, Osvaldo y Gelman, Jorge, Historia del agro argentino. Desde la conquista hasta fines del siglo XX, Buenos Aires, Grijalbo, 2001.

Bejarano, Manuel, «Inmigración y estructuras tradicionales en Buenos Aires (18541930)», Di Tella, Torcuato y Halperin Donghi, Tulio, Los fragmentos del poder, Buenos Aires, Editorial Álvarez, 1969: 75-149.

Bellingeri, Marco y Gil Sánchez, Isabel, «Las estructuras agrarias», Cardoso, Ciro (coord.), México en el siglo XIX (1821-1910): historia económica y de la estructura social, México, Editorial Nueva Imagen, 1980: 97-118.

Cárcano, M. Á., Evolución histórica del régimen de la tierra pública, Buenos Aires, Eudeba, 1972 [1917]. 
Congost, Rosa, Tierras, leyes, historia. Estudios sobre «la gran obra de la propiedad», Barcelona, Critica, 2007.

De la Peña, Guillermo, Herederos de Promesas. Agricultura, política y ritual en los Altos de Morelos, México, Ediciones de la Casa Chata, 1980.

Díaz Couselo, José María, «La tradición indiana y la formación del derecho argentino», Revista Temas de Historia argentina y americana, Instituto de Historia Argentina y Americana, 7 (Buenos Aires, 2005): 43-74.

Djenderedjian, Julio, Historia del capitalismo agrario pampeano. Tomo 4. La agricultura pampeana en la primera mitad del siglo XIX, Buenos Aires, Universidad de Belgrano-Siglo XXI editores, 2008.

Eckstein, Salomón, El ejido colectivo en México, México, FCE, 1966.

Escriche, Joaquín, Diccionario razonado de legislación y jurisprudencia, Madrid, Imp. de E. Cuesta, 1851.

Fradkin, Raúl, «Entre la ley y la práctica: la costumbre en la campaña bonaerense de la primera mitad del siglo XIX», Anuario del IEHS, 12 (Tandil, 1997): 141-156.

Fradkin, Raúl y Gelman, Jorge, «Recorridos y desafíos de una historiografía. Escalas de observación y fuentes en la historia rural rioplatense», Bragoni, Beatriz (ed.), Microanálisis. Ensayos de historiografía argentina, Buenos Aires, Prometeo Libros, 2004: 31-54.

Gelman, Jorge, Un funcionario en busca del Estado. Pedro Andrés García y la cuestión agraria bonaerense, 1810-1822, Quilmes, Universidad Nacional de Quilmes, 1997.

Grossi, Paolo, La propiedad y las propiedades. Un análisis histórico, Madrid, Civitas, 1992.

Halperin Donghi, Tulio, «La expansión ganadera de la campaña de Buenos Aires (1810-1852)», Di Telia, T. y Halperin Donghi, T. (comps.), Los fragmentos del poder, Buenos Aires, Editorial Álvarez, 1969: 21-73.

Infesta, María Elena y Valencia, Marta, «Tierras, premios y donaciones, 1830- 1860», Anuario IEHS, 2 (Tandil, UNCPBA, 1987): 177-213.

Jaime Lorén, José M. a de y Jaime Gómez, José de, «JOAQUÍN ESCRICHE Y MARTÍN (Caminreal, 1784-1847). Fue eminente jurisconsulto, magistrado, publicista, codificador entendido... Fue liberar, XILOCA 24, Centro de Estudios del Jiloca Aragón, España, 1999: 115-129.

Knowlton, Robert J., «El ejido mexicano en el siglo XIX», Historia Mexicana, XLVIII/1 (Ciudad, 1998): 71-96.

Mariluz Urquijo, José M., El régimen de la tierra en el derecho indiano, Buenos Aires, Perrot, 1978. 
Martiré, Eduardo, «El Derecho Indiano: un derecho propio particular», Revista de Historia del Derecho, 29 (Buenos Aires, 2001): 331-361.

Mendieta y Núñez, Lucio, El problema agrario de México, México, Porrua, 1964.

Menegus, Margarita y Cerrutti, Mario (eds.), La desamortización civil en México y España, 1750-1920, México, Senado de la República-UANL-UNAM, 2001.

Muzlera, Joaquín, Tierras Públicas. Recopilación de leyes, decretos y resoluciones de la provincia de Buenos Aires sobre tierras públicas desde 1810 a 1895. La Plata, Isidro Solá Sanz (s/f).

Orozco, Winstano Luis, Legislación y jurisprudencia sobre terrenos baldíos, México, Imprenta de El Tiempo, Leandro Valle, 1895.

Ots Capdequí, José María, Manual de historia del derecho español en las Indias y del derecho propiamente indiano, Buenos Aires, Facultad de Derecho y Ciencias Sociales, 1946.

Page, Carlos, «Los ejidos como espacio comunal de la ciudad de Córdoba del Tucumán», Revista de Indias, 64/232 (Madrid, 2004): 635-650.

Peset, Mariano, «La desamortización civil en España», Menegus, Margarita y Cerrutti, Mario (eds.), La desamortización civil en México y España, 1750-1920, México, Senado de la República-UANL-UNAM, 2001.

Sabato Hilda y Korol, Juan Carlos, Cómo fue la inmigración irlandesa en Argentina, Buenos Aires, Editorial Plus Ultra, 1981.

Samudio, Edda, «Las tierras comunales indígenas, un propósito o una realidad. El caso de Mérida», Boletín de la Academia Nacional de Historia, Tomo LXXXIX, 353, enero-marzo 2006: 63-98.

Tabossi, Ricardo, Historia de la Guardia de Lujan durante el período hispano indiano, La Plata, Archivo Histórico de la Provincia de Buenos Aires, 1980.

Tau Anzoategui, Víctor, «La costumbre en el Derecho Civil Argentino del siglo XIX. De la Revolución al Código Civil», Revista de Historia del Derecho, 4, Buenos Aires, 1976: 231-303.

Tau Anzoategui, Víctor, «Consideraciones sobre la aplicación de la Recopilación de 1680», Revista de Historia del Derecho, 8 (Buenos Aires, 1980): 331-395.

Tau Anzoategui, Víctor, «La costumbre jurídica en la América Española (siglos XVIXVIII)», Revista de Historia del Derecho, 14 (Buenos Aires, 1986): 355-425.

Tau Anzoategui, Víctor, Las ideas jurídicas en la Argentina (Siglos XIX-XX), Buenos Aires, Perrot.

Tau Anzoategui, Víctor, «El tejido histórico del Derecho Indiano. Las ideas directivas de Alfonso Díaz Gallo», Revista de Historia del Derecho, 21 (Buenos Aires, 1993): 41-51. 
Tell, Sonia, «Expansión urbana sobre tierras indígenas. El pueblo de La Toma en la Real Audiencia de Buenos Aires», Mundo Agrario, 20 (La Plata, 2010): en línea.

Valencia, Marta, Tierras públicas, Tierras privadas. Buenos Aires 1852-1876, La Plata, Edulp, 2005.

Zeberio, Blanca, «Los hombres y las cosas. Cambios y continuidades en los derechos de propiedad (Argentina, siglo XIX)», Quinto Sol (2005-2006): 151-183.

Zorraquín Becú, Ricardo, «Hacia una definición del Derecho Indiano», Revista de Historia del Derecho, 22 (Buenos Aires, 1994): 401-417.

Zorraquín Becú, Ricardo, «Nuevas consideraciones sobre el Derecho Indiano», Revista de Historia del Derecho, 25 (Buenos Aires, 1997): 501-524.

Fecha de recepción: 17 de septiembre de 2010

Fecha de aceptación: 23 de febrero de 2011

\section{The influence of the Indian Law on the legislation of common land in the Province of Buenos Aires, 1782-1870}

The villages of the present day province of Buenos Aires were mostly formed spontaneously, as the population settled and moved into the indigenous space;in the majority of the cases by force or under the protection of the church. The communal land of these people existed, in fact, as land for growing cereals, but wasonly formally set recently during the 19th Century.Throughout this work, we will analyze the method in which a legal body was put together for the Buenos Aires communal land especially emphasising the influence of the Indian law.

KEY WORDS: common land, villages, Buenos Aires, Indian Law, donations, property, farmworkers. 